\title{
ELECTROCHEMICAL REDOX OF ACETAMINOPHEN MEDIATED BY FUNCTIONALIZE MWCNT MODIFIED GLASSY CARBON ELECTRODE
}

\author{
Zahraa Naji Kareem \\ Technical Engineering College-Baghdad, Middle Technology University, Baghdad, (MTU) Iraq, \\ Muhammed Mizher Radhi \\ Radiological Techniques Department, Health and Medical Technology College-Baghdad, Middle Technology \\ University, Baghdad, (MTU) Iraq. \\ Ahmed Ali Moosa \\ Technical Engineering College-Baghdad, Middle Technology University, Baghdad, (MTU) Iraq,
}

Abstract- Glassy carbon electrode (GCE) was modified with functionalize multi wall carbon nanotubes (fMWCNT) by a mechanical attachment technique to produced modified electrode fMWCNT/GCE. The modified working electrode (fMWCNT/GCE) was used to study paracetamol compound (PAR) in KCl solution by cyclic voltammetric technique to find the electrochemical properties of different concentrations, scan rates, $\mathrm{pH}$, diffusion coefficient and reliability. Two oxidation and one reduction current peaks of PAR were found at 750, 375, and $200 \mathrm{mV}$ respectively. PAR compound was examined using the modified electrode to identify the behavior of this compound through oxidation and reduction properties. Good relationships of different concentrations, scan rate, pH of PAR in the electrolyte to prove the sensitive sensor of the modified electrode against to the PAR compound. Diffusion coefficient $\left(D_{f}\right)$ values was determined from Randal equation which has closed values of two oxidation and one reduction peaks of $D_{\mathrm{f}}\left(I_{\mathrm{pa}} 1\right)=3.06 \times 10^{-6}, D_{\mathrm{f}}\left(I_{\mathrm{pa}} 2\right)=$ $5.43 \times 10^{-6}$, and $D_{\mathrm{f}}\left(\mathrm{I}_{\mathrm{pc}}\right)=1.96 \times 10^{-6}$ respectively. The search concluded that PAR acts as oxidative drug in alkaline medium and antioxidant in acidic medium.

Keyword- Paracetamol, Cyclic voltammetry, fMWCNT, GCE, KCl.

\section{INTRODUCTION}

Paracetamol (acetaminophen-N-acetyl-p-aminophenol, PCM) $\left(\mathrm{C}_{8} \mathrm{H}_{9} \mathrm{NO}_{2}\right)$ is a crystalline white powder with a bitter taste, is odourless, and has a molecular weight of 151.169 About $90 \%$ of acetaminophen reacts with $30 \%$ sulphate and $60 \%$ glucuronide in the liver [1-3].

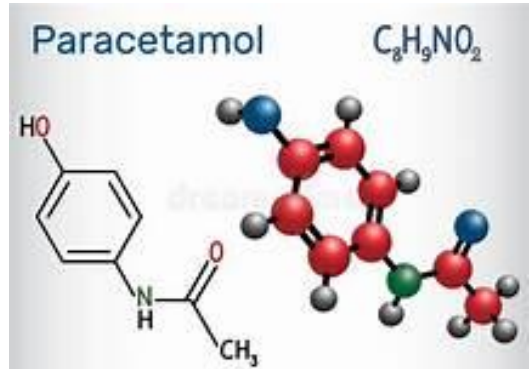

Fig. 1. paracetamol structure

Recently, there is an increasing in the synthesis, use, sensitive analysis, and means of delivery of drug active compounds used in the diagnosis, prevention, and treatment of human and animal's diseases. The analyses of smaller amounts of biological samples such as blood, serum and urine are often requested. This required accurate and sensitive methods for the determination of pharmaceuticals in small sample. A powerful and versatile analytical technique such as electrochemical techniques is more regularly used on the drug analysis in biological samples [4].

Biosensor is a diagnostic device that converts a biological event into a measurable electrical signal. One of the a major obstacle for CNTs applications as biosensors is the dispersion problem caused by the CNTs high surface energy where CNTs tend to aggregate into bundles due to the strong attractive interactions, which are very difficult to disrupt. They have highly hydrophobic surfaces and are not soluble in water or any common solvents [5]. In order to improve the solubility and stability of CNTs, different functional groups will be introduced on the surface of CNTs using covalent and noncovalent procedures [6]. During oxidizing treatment several functional groups such as carbonyl, carboxyl and hydroxyl are 
also created at the defect sites of the outer graphene sheet. These groups reduce the van der Waals interactions between CNTs and enable further modifications to covalently connect with other molecules $[7,8]$.

Glassy carbon is a solid isotropic material consist of thin convoluting micro fibbers that joined together to form interfibrillary have strong bonds [9]. Although, glassy carbon electrode as a very good electrode but many attempts have been done to improve its electrochemical properties by chemical or physical modification [10]. The use of conventional material electrodes usually requires high potentials for the electro-oxidation of target materials; consequently, relatively high detection limits were reached. In order to eliminate these drawbacks, different modified electrodes have been proposed [11]. Glassy carbon electrode is widely used because of its high chemical resistance, high electrical conductivity, impermeability to gases, dimensional stability, and widest potential range [12]. The use of modified electrodes proved to have excellent electroanalytical properties, such as lowering the background current, enhancement of the voltammetric peak response and increasing sensitivity [13]. Recently, nanoparticle modified electrodes have been proposed for the determination of paracetamol in pharmaceutical preparations including electrodeposition of metal nanoparticles, such as $\mathrm{Ru}, \mathrm{Cu}$, gold , in addition to Fullerene and carbon nanotubes ( CNT) [14]. In this study a new modified glassy carbon electrode (GCE) with functionalize multi wall carbon nanotubes (fMWCNT) fMWCNT/GCE was prepared to voltammetric characterization of paracetamol compound.

\section{EXPERIMENTAL}

\section{A. Materials}

Paracetamol (Hebei Jiheng (Groups) Pharmaceutical CO., LTD., China), Carboxyl Multi Wall Carbon Nanotubes (Neutrino Co., New York, USA), $\mathrm{KCl}$ powder from SCRC, (China), $\mathrm{NaOH}$ from BDH Company, $0.1 \mathrm{~N} \mathrm{HCl}$ solution and deionized water were used in this study.

\section{B. Equipment}

Cyclic Voltammetry (EZST 12051401, NuVant Systems, Inc.Crown Point, Indiana, USA) is used in the area of this work. In general, the Biochemical Analytical Chemistry Cell has been linked to a powerful instrument and monitored by the Special Program for Measuring Periodic Periodic Voltage (CV). As a reference electrode, silver / silver chloride (Ag / $\mathrm{AgCl})$ at $3 \mathrm{M} \mathrm{KCl}$ was used, while a platinum wire auxiliary electrode with a diameter of $1 \mathrm{~mm}$ was used. Also in this study glassy carbon electrode (GCE) was used after cleaning with alumina solution and treated with ultrasonic pathway water for 10 minutes. Using the mechanical attachment method with nanoparticle powder the other working electrode was modified with Functionalize fCNT / GCE [15]. The three electrodes are inundated in a cyclic voltammetic cell $(10 \mathrm{ml})$ with electrolyte.

\section{RESULTS AND DISCUSSION}

\section{A. Effect of different electrodes}

Figure 2 shows the oxidation-reduction current peaks of paracetamol were considerably enhanced by 4-5 times when fMWCNT /GCE were used in comparison with bar GCE. Evidently degree of sensitivity response increases in the order of: fMWCNT /GCE > GCE. So, the nanomaterials act as electrochemical catalyst by enhancement the conductivity.

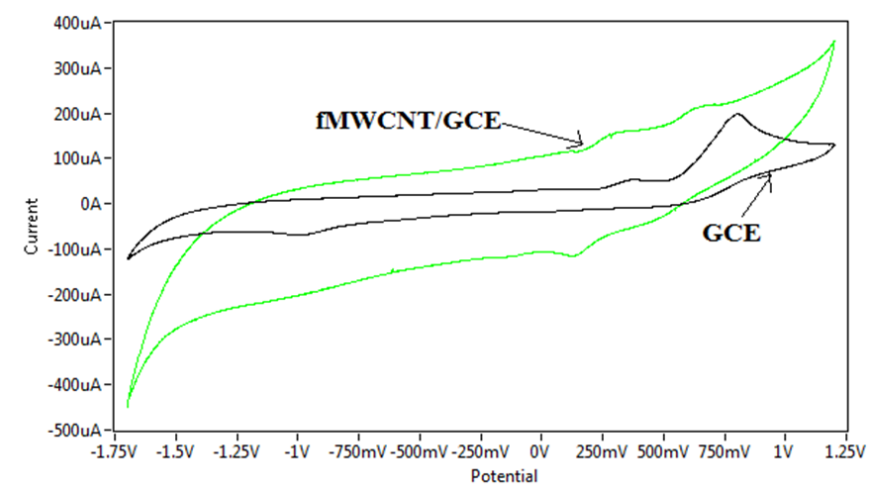

Fig. 2. Compared between modified electrode

(fMWCNT/GCE) and GCE in $1 \mathrm{M} \mathrm{KCl}$ as an electrolyte with $0.38 \mathrm{mM}$ Paracetamol.

\section{B. Effect of Varying Supporting Electrolytes}

The effect of different supporting electrolytes was studied $1 \mathrm{M}$ of $\mathrm{KH}_{2} \mathrm{PO}_{4}, \mathrm{KCl}, \mathrm{KClO}_{4}, \mathrm{KNO}_{3}$ and $\mathrm{NaCl} 0.1 \mathrm{mM}$ with PAR on the modified GCE (fMWCNT/GCE) as working electrode. Table 1 and 2 illustrated that $\mathrm{KCl}$ solution as an electrolyte has enhanced the redox current peaks with order with the other electrolytes:

Oxidation peak: $\mathrm{KCl}>\mathrm{KNO}_{3}>\mathrm{KH}_{2} \mathrm{PO}_{4}>\mathrm{NaCl}>\mathrm{KClO}_{4}$ Reduction peak: $\mathrm{KCl}>\mathrm{KH}_{2} \mathrm{PO}_{4}>\mathrm{NaCl}>\mathrm{KClO}_{4}$ 
International Journal of Engineering Applied Sciences and Technology, 2020

Vol. 5, Issue 2, ISSN No. 2455-2143, Pages 127-136

Published Online June 2020 in IJEAST (http://www.ijeast.com)

Table 1: Oxidation current and potential peak of $0.1 \mathrm{mM}$ PAR in $1 \mathrm{~m}$ of different electrolytes at scan rate $0.1 \mathrm{Vs}^{-1}$ on the fMWCNT/GCE and GCE.

\begin{tabular}{|c|c|c|c|c|c|}
\hline Electrolyte & $\begin{array}{c}\text { Ipa(pA) } \\
\text { fMWCNT } \\
\text { /GCE }\end{array}$ & $\begin{array}{c}\operatorname{Epa}(\mathbf{m V}) \\
\text { fMWCNT } \\
/ \mathrm{GCE}\end{array}$ & $\begin{array}{c}\operatorname{Ipa}(\boldsymbol{\mu A}) \\
\mathrm{GCE}\end{array}$ & $\begin{array}{c}\mathrm{Epa}(\mathrm{mV}) \\
\text { GCE }\end{array}$ & Enhancement \\
\hline $\mathrm{KCl}$ & 208 & 677 & 48.8 & 344 & 4.262 \\
\hline $\mathrm{KNO}_{3}$ & 522 & 933 & 150 & 692 & 3.48 \\
\hline $\mathrm{KH}_{2} \mathrm{PO}_{4}$ & 345 & 752 & 185 & 719 & 1.864 \\
\hline $\mathrm{KClO}_{4}$ & 179 & 789 & 130 & 746 & 1.376 \\
\hline $\mathrm{NaCl}$ & 231 & 794 & 158 & 757 & 1.462 \\
\hline
\end{tabular}

Table 2: Reduction current and potential peak of $0.1 \mathrm{mM}$ PAR in $1 \mathrm{~m}$ of different electrolytes at scan rate $0.1 \mathrm{Vs}^{-1}$ on the fMWCNT/GCE and GCE

\begin{tabular}{|cccccc|} 
Electrolyte & $\begin{array}{c}\text { Ipc( }(\mu \mathrm{A}) \\
\text { fMWCNT } \\
/ G C E\end{array}$ & $\begin{array}{c}\text { Epc(mV) } \\
\text { fMWCNT } \\
/ \text { GCE }\end{array}$ & $\begin{array}{c}\text { Ipc( }(\mu \mathrm{A}) \\
\text { GCE }\end{array}$ & $\begin{array}{c}\text { Epc(mV) } \\
\text { GCE }\end{array}$ & Enhancement \\
\hline $\mathrm{KCl}$ & -107 & 151 & -41 & 92.1 & 2.609 \\
\hline $\mathrm{KNO}_{3}$ & - & - & - & - & - \\
\hline $\mathrm{KH}_{2} \mathrm{PO}_{4}$ & -150 & 376 & -57 & 569 & 2.631 \\
\hline $\mathrm{KClO}_{4}$ & -40.6 & 505 & -37.8 & 569 & 1.074 \\
\hline $\mathrm{NaCl}$ & -60 & 521 & -44.4 & 623 & 1.351 \\
\hline
\end{tabular}

\section{Effect Different Concentrations of PAR on fMWCNT /} GCE

The modified electrode (fMWCNT / GCE) was used to study the effect of different PAR concentration $(0.02-0.38 \mathrm{mM})$ in $1 \mathrm{M} \mathrm{KCl}$ at constant temperature $\left(25^{\circ} \mathrm{C}\right)$ and scan rate of 0.1 $\mathrm{Vsec}^{-1}$ as shown in Fig. 3. The oxidation - reduction current peaks of PAR were enhanced with increasing the concentration which indicated that PAR ions diffused through the electrolyte to the modified electrode (fMWCNT / GCE) [16].
Fig. 4 illustrated the relationship between the two anodic and cathodic current peaks against to the increasing the concentration of PAR on the new modified electrode (fMWCNT / GCE), it was found from the results that the following equations of the good linear lines with high values of sensitivity:

Ipa (1): $\mathrm{Y}=55.293 \mathrm{X}+193.03$ with $\mathrm{R} 2=0.9035$

Ipa (2): $\mathrm{Y}=42.204 \mathrm{X}+143.32$ with $\mathrm{R} 2=0.9017$

Ipc: $\quad \mathrm{Y}=-45.19 \mathrm{X}-101.99 \quad$ with $\mathrm{R} 2=0.7287$

The suggesting of the mechanism for the redox reaction of paracetamol in electrochemistry can be discussed by the following reaction:<smiles>C=C(O)N=C1C=CC(=O)C=C1</smiles><smiles>CC(=O)Nc1ccc(O)cc1</smiles><smiles>CC(=O)N=C1C=CC(=O)C=C1</smiles> 
Published Online June 2020 in IJEAST (http://www.ijeast.com)

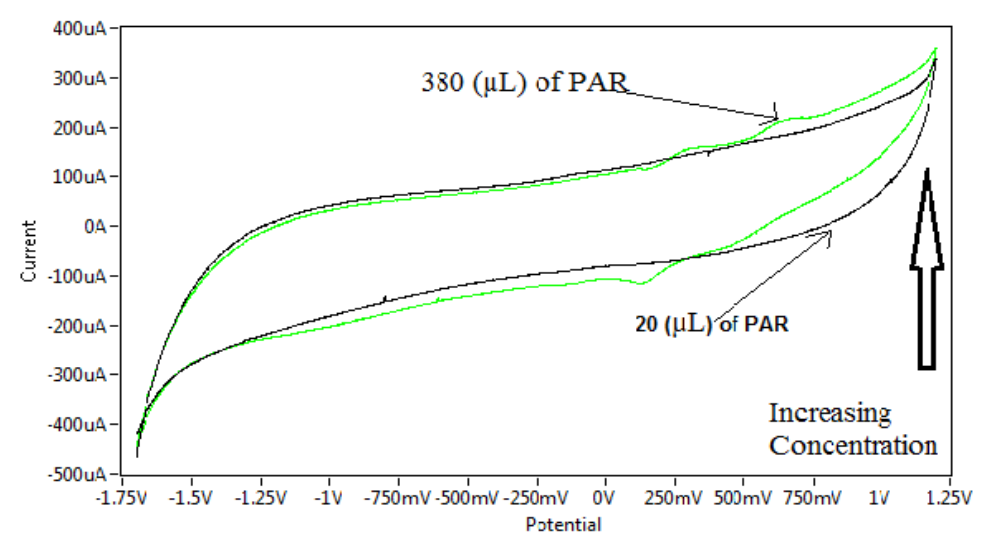

Fig. 3: Cyclic Voltammogram of different concentration of $(0.02-0.380 \mathrm{mM})$ of PAR in $1 \mathrm{M} \mathrm{KCl}$ on the modified electrode (fMWCNT / GCE) Versus Ag/AgCl as Reference Electrode at Scan Rate $0.1 \mathrm{Vsec}^{-1}$

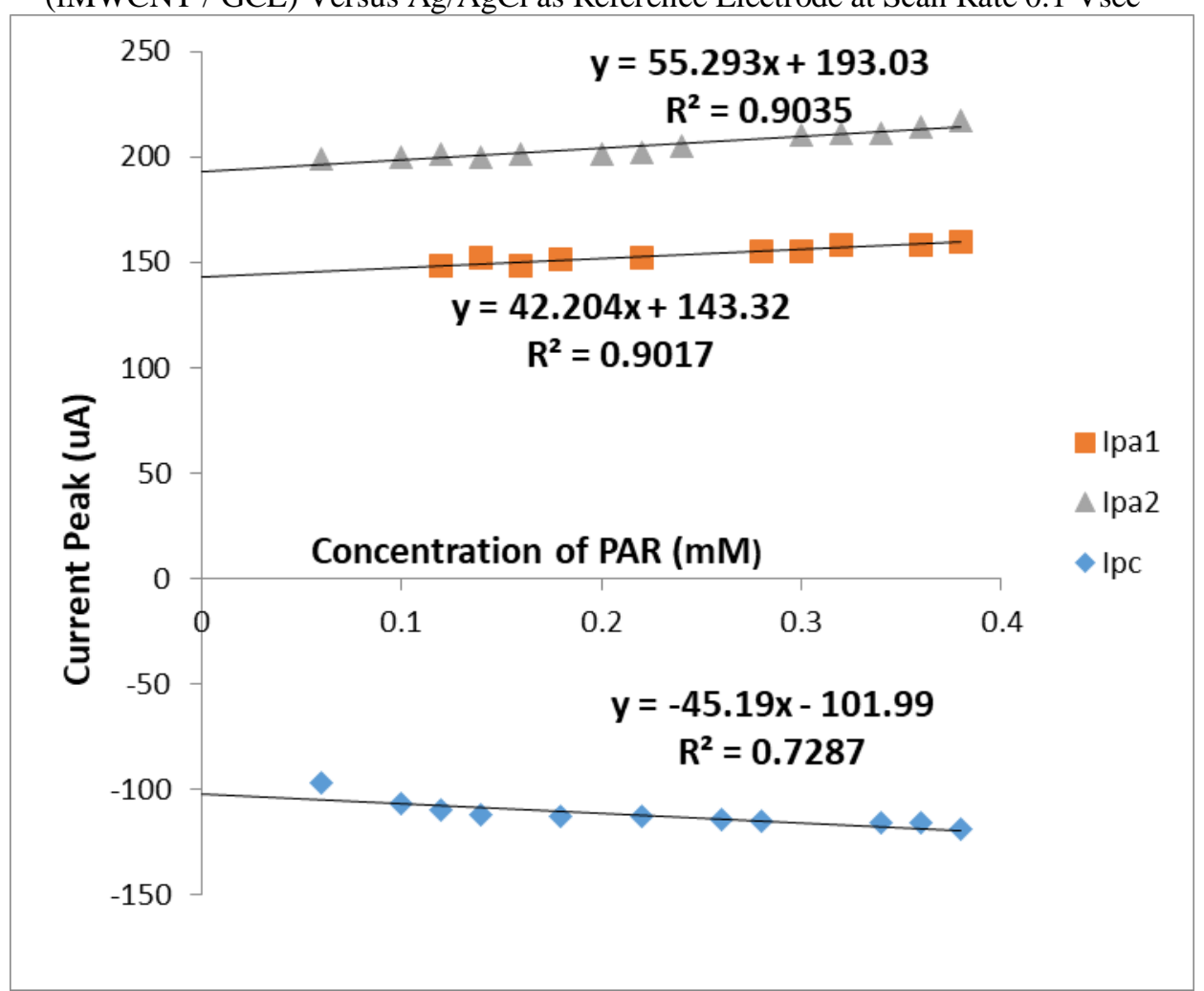

Fig. 4. Relationship between anodic and cathodic current peaks against to the different concentration (0.02-0.38 mM) of PAR on the modified electrode (fMWCNT/GCE).

\section{Effect of Different Scan Rates}

Different scan rate from 0.01 to $0.1 \mathrm{Vsec}^{-1}$ was studied for the oxidation-reduction current peaks of $0.38 \mathrm{mM}$ PAR in $1 \mathrm{M}$ $\mathrm{KCl}$ on the modified electrode (fMWCNT / GCE) as shown in Fig. 5. It was found an increasing of the oxidation - reduction current peaks with good linear relationships against to the increasing of scan rates as shown in Fig. 6. The two oxidation peaks and one reduction peak were mentioned on the Fig. 5 with high sensitivity values of the relationships in the below equations [17]:

The linear regression equations:
$\mathrm{I}_{\mathrm{pal}}(\mathrm{y}=1274.1 \mathrm{x}+44.607)$
$\mathrm{R}^{2}=0.9177$
$\mathrm{I}_{\mathrm{pa} 2}(\mathrm{y}=1432.1 \mathrm{x}+71.607)$
$\mathrm{R}^{2}=0.9873$
$I_{p c}\left(y=-1016.4 x_{-}\right.$23.027)
$\mathrm{R}^{2}=0.9212$ 
Published Online June 2020 in IJEAST (http://www.ijeast.com)

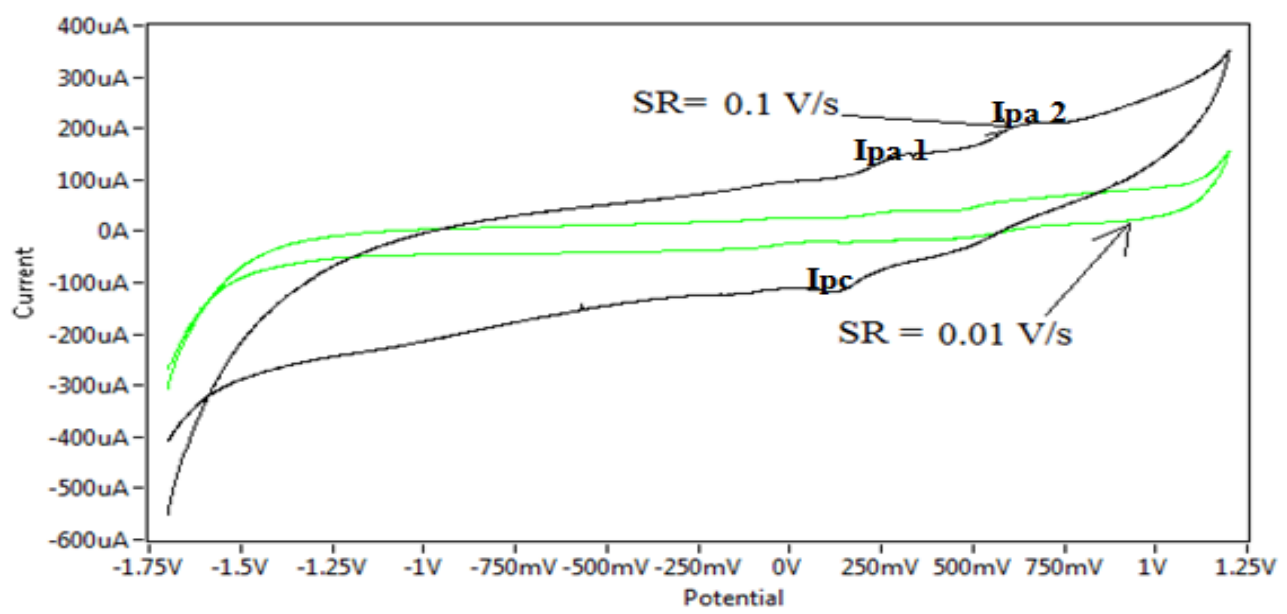

Fig. 5 Cyclic voltammogram of PAR at different scan rate 0.01-0.1 Vs-1

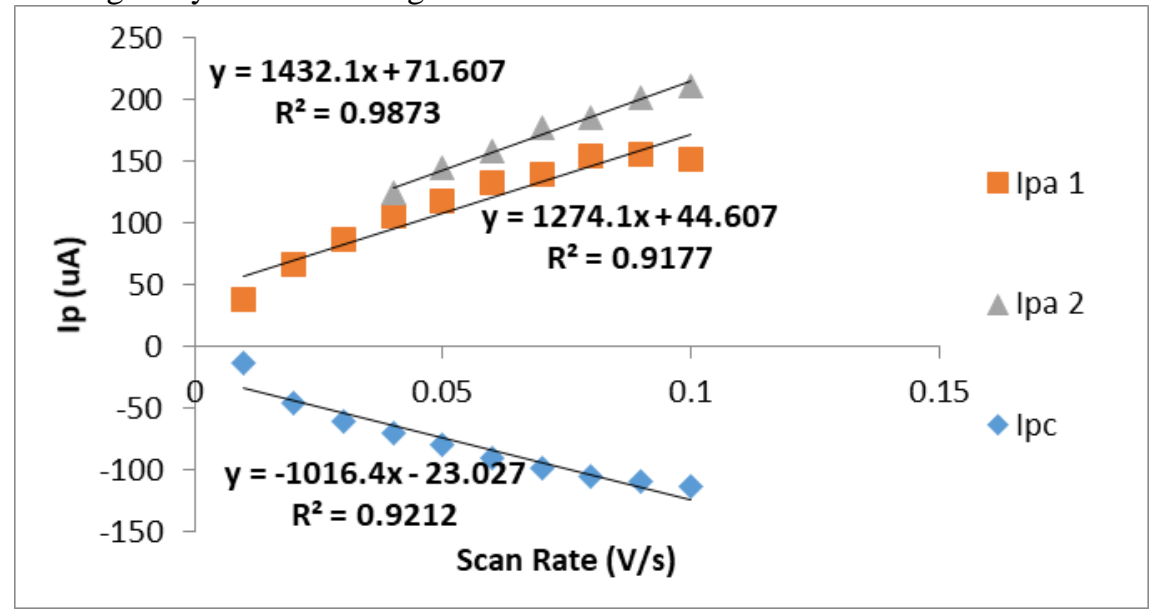

Fig. 6: Relationship between anodic and cathodic current peaks against to the different scan rates (0.01-0.1 Vs-1) of PAR on the modified electrode (fMWCNT/GCE).

\section{E. Determination of Diffusion Coefficient}

The diffusion coefficient determined by using Randles-Seveik equation as show in the below equation. The Randles-Sevcik equation was used to describe the effect of scan rate on the current peak (Ip).

$$
\begin{gathered}
\mathrm{Ip}=\left(2.69 \times 10^{5}\right) n^{\mathrm{a} / 2} \text { A C D } \mathrm{f}_{\mathrm{f}}^{1 / 2} v^{1 / 2} \\
\text { Where }
\end{gathered}
$$

- $i_{p}=$ current maximum in amps

- $n=$ number of electrons transferred in the redox event

- $A=$ electrode area in $\mathrm{cm}^{2}$

- $\quad D=$ diffusion coefficient in $\mathrm{cm}^{2} / \mathrm{s}$

- $C=$ concentration in $\mathrm{mol} / \mathrm{cm}^{3}$

- $\quad v=$ scan rate in $\mathrm{V} / \mathrm{s}$
The diffusion coefficient values of two anodic peaks and one cathodic peak of PAR on the new modified working electrode (fMWCNT/GCE) was calculated from the slope values of the relationships finding from Fig. 7 and 8, with the Randel equation, the values of diffusion coefficient are calculated below:

$$
\begin{aligned}
\mathrm{D}_{\mathrm{f}}\left(\mathrm{I}_{\mathrm{pa}} 1\right) & =3.06 \times 10^{-6} \\
\mathrm{D}_{\mathrm{f}}\left(\mathrm{I}_{\mathrm{pa}} 2\right) & =5.43 \times 10^{-6} \\
\mathrm{D}_{\mathrm{f}}\left(\mathrm{I}_{\mathrm{pc}}\right) & =1.96 \times 10^{-6}
\end{aligned}
$$

The modification of GCE with nanoparticles such as fMWCNT, which has a new phenomenon of the electrochemical conductivity in the cyclic voltammetry by enhancement the redox current that leading to the close diffusion coefficient values as in the above values. These results were indicated that the oxidation-reduction process of the paracetamol compound is a reversible reaction on the modified electrode (fMWCNT/GCE) [18]. 


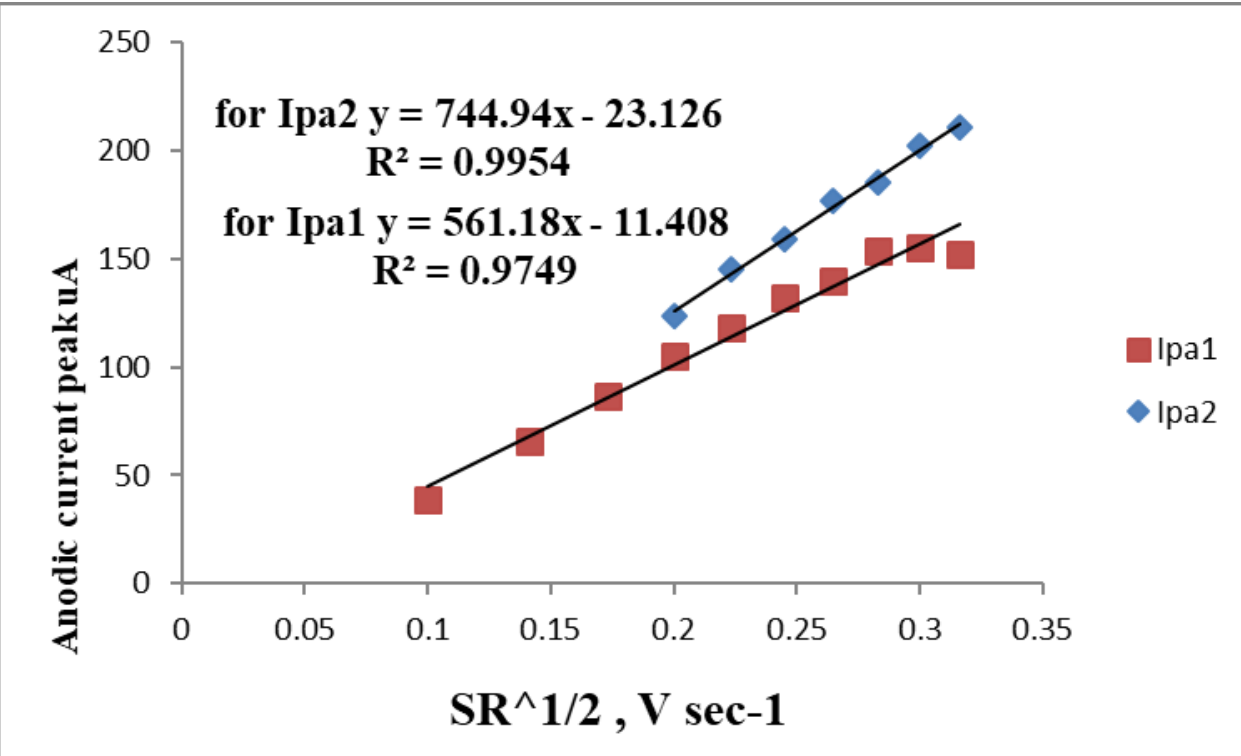

Fig. 7: Relationship between anodic current peak $0.38 \mathrm{mM}$ of PAR versus different square root scan rate.

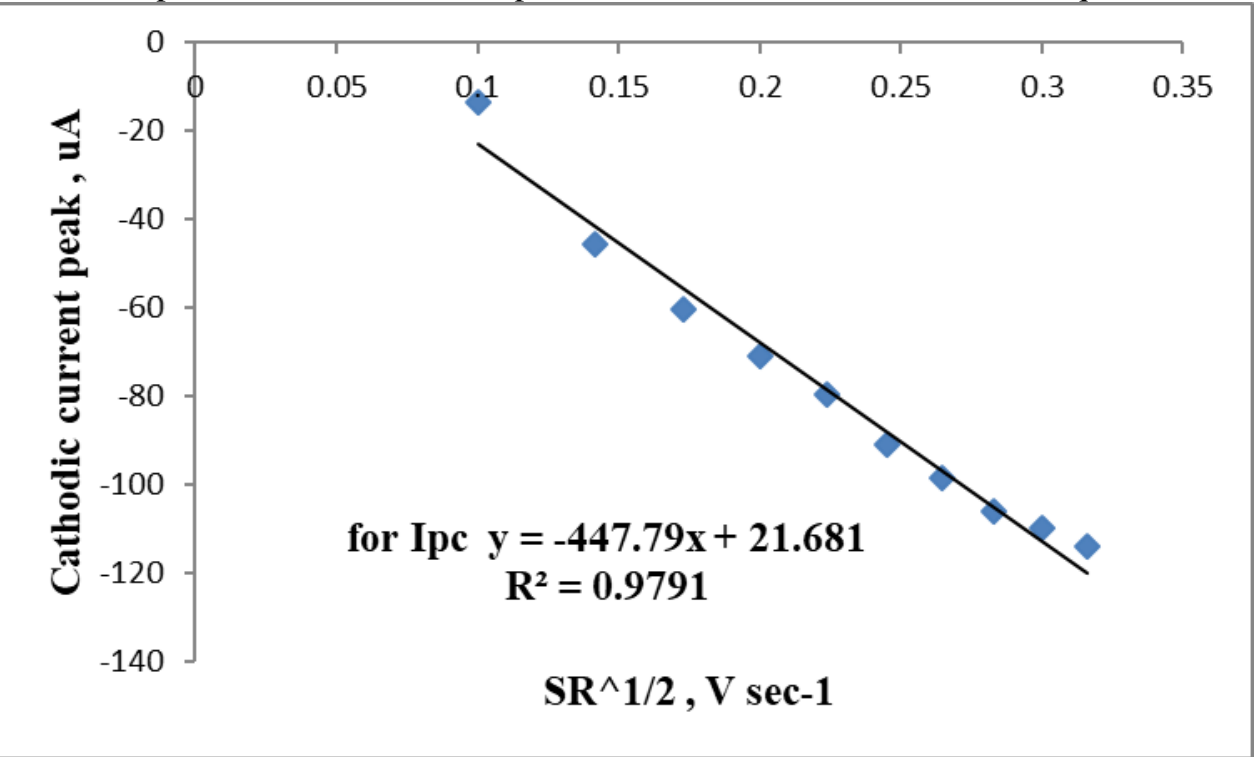

Fig. 8: Relationship between cathodic current peak $0.38 \mathrm{mM}$ of PAR versus different square root scan rate.

\section{F. Effect of Different pH}

The effect of $\mathrm{pH}$ to find the response of PAR in $\mathrm{KCl}$ solution on the modified electrode (fMWCNT/GCE) was studied in the range of $\mathrm{pH}$ 3-12. Fig. 9 illustrated cyclic voltammograms scanning at different $\mathrm{pH}$ values of $0.38 \mathrm{mM}$ PAR. The different $\mathrm{pH}$ media has a significant influence by enhancement on the oxidation-reduction current peaks which shifted to higher potential peaks in $\mathrm{pH}$ alkaline. It means that the catalytic of both oxidation-reduction peaks for the PAR in alkaline medium $(\mathrm{pH}=12)$. Fig. 10 shows the oxidation current peak of PAR has maximum value in alkaline $\mathrm{pH}$, because the alkaline medium acts as electro-catalyst agent of oxidative effect of PAR in this $\mathrm{pH}[19,20]$. 


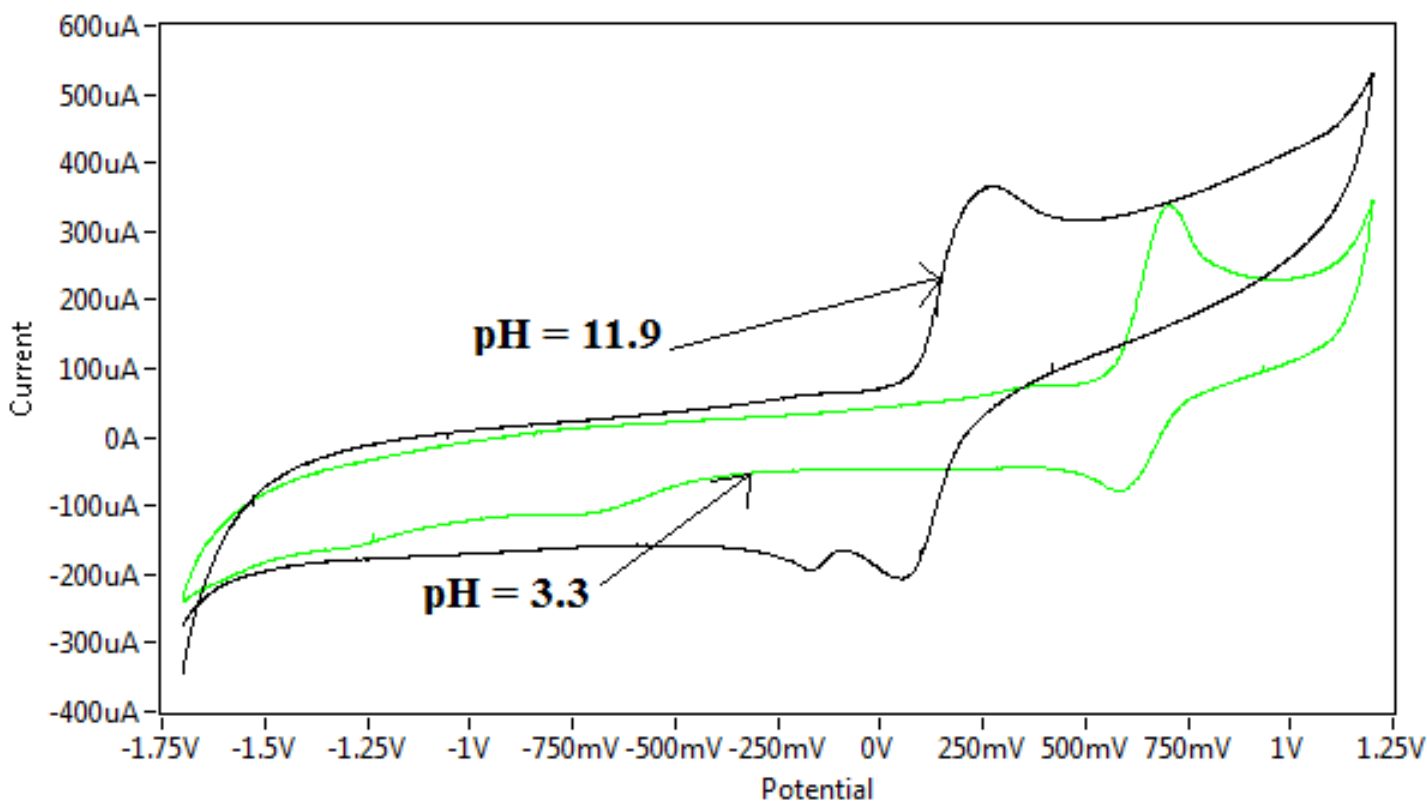

Fig. 9: Cyclic voltammogram $0.38 \mathrm{mM}$ PAR in $\mathrm{pH} 12$ and 3 on modified electrode fMWCNT/GCE.

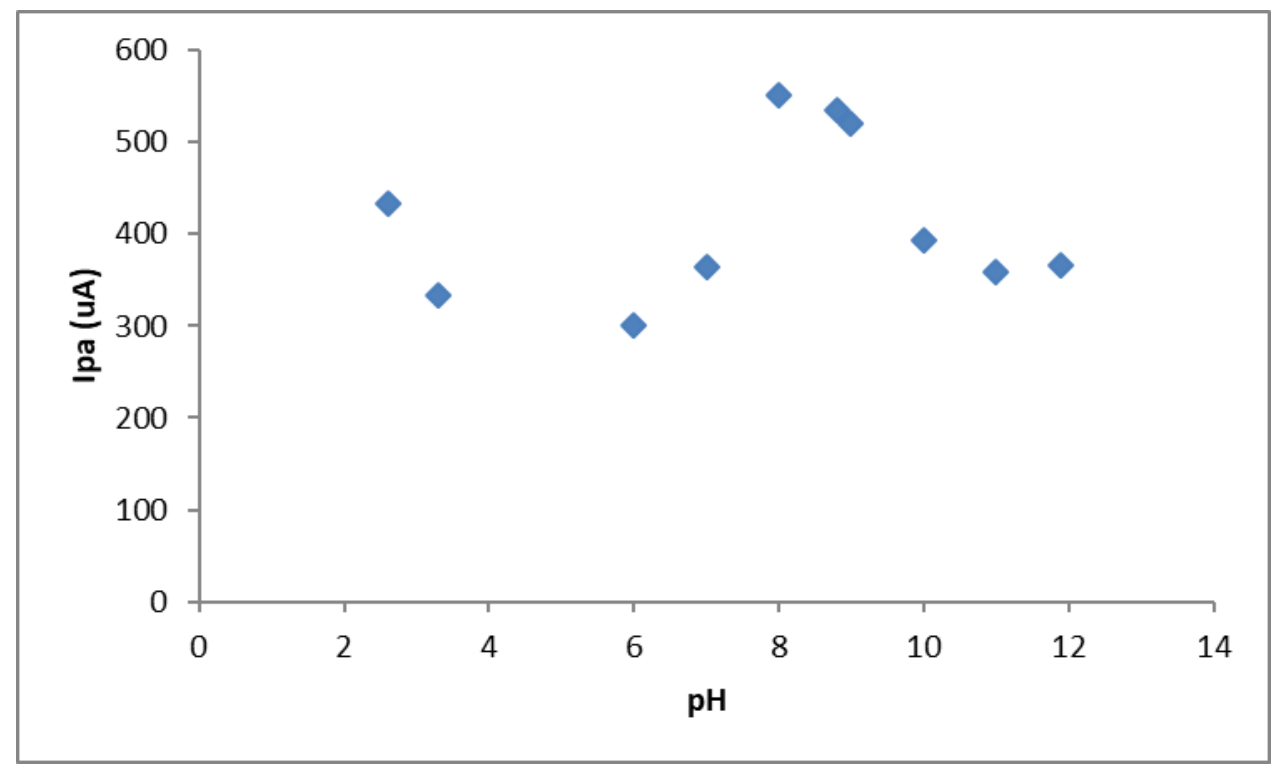

Fig. 10: Relationship between Anodic Current Peaks versus Different pH.

\section{F. Reliability and Stability Study}

The reliability and stability of the modified electrode (fMWCNT/GCE) was used PAR at ten times to study the oxidation - reduction reaction. Fig. 11 and table 3 show the values of the cyclic voltammogram at ten times and the relative standard deviation (RSD) for the oxidation and reduction process of $0.38 \mathrm{mM}$ PAR, respectively.

From Fig. 11 ,the cyclic voltammogram of PAR at ten times on the modified electrode (fMWCNT/GCE) versus $\mathrm{Ag} / \mathrm{AgCl}$ as a reference electrode, shows not much interruption in the peak currents or peak potentials. This indicates that the fMWCNT was stably adhered to the GCE electrode surface. It was found from the results of table 3 that the RSD values of two oxidation current peaks and one reduction current peak of PAR on modified electrode (fMWCNT/GCE) has suitable values of $\pm 3.423 \%, \pm 2.3604 \%$, and $\pm 4.734 \%$, respectively which indicates that the nanoparticles of fMWCNT has a good stability on the surface of GCE. 
Published Online June 2020 in IJEAST (http://www.ijeast.com)

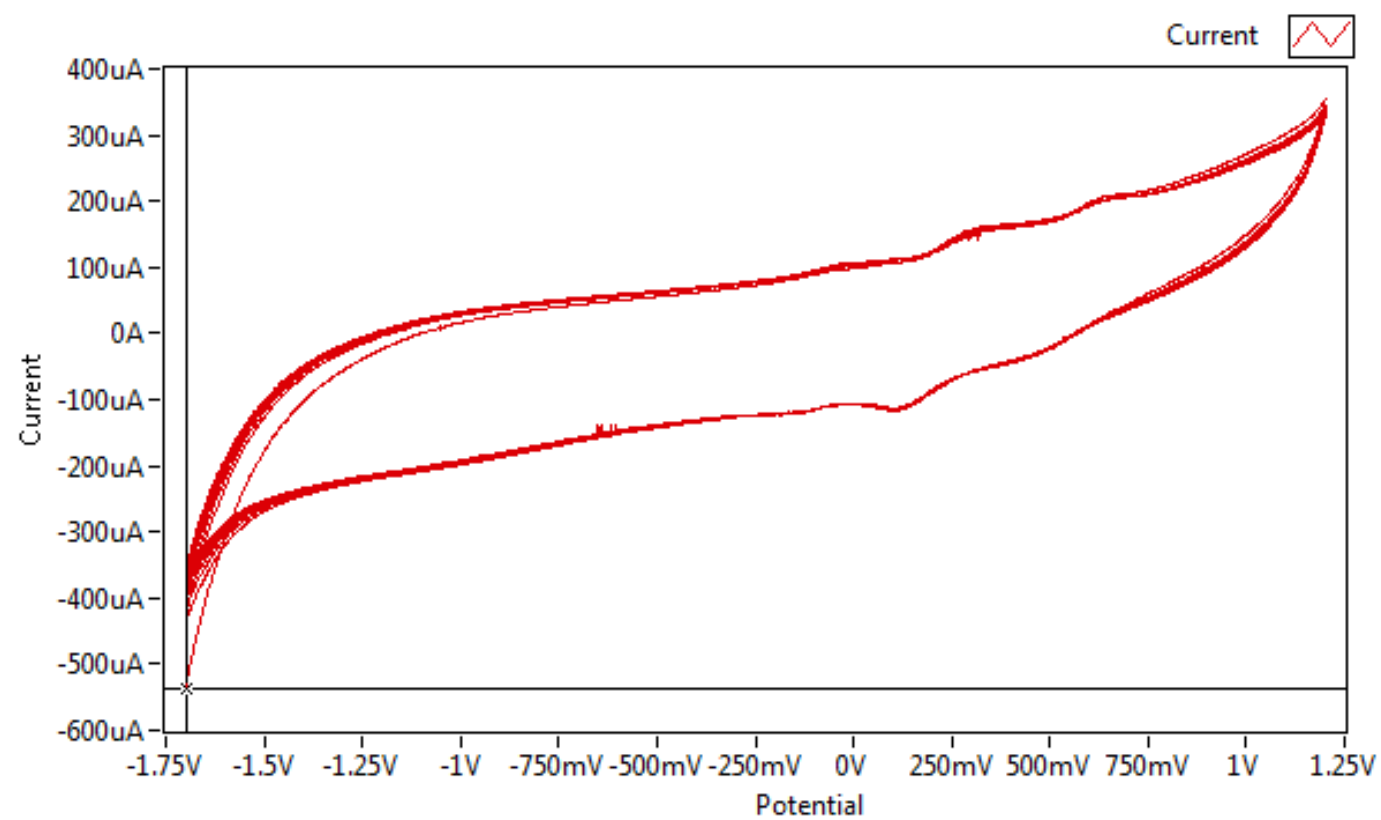

Fig. 11: Cyclic voltammogram of $0.38 \mathrm{mM}$ PAR at ten times on the modified electrode (fMWCNT/GCE) versus $\mathrm{Ag} / \mathrm{AgCl}$ as a reference electrode

Table 3: Relative standard deviation (RSD) of the stability for modified working electrode (fMWCNT/GCE) of oxidation reduction current peaks of $0.38 \mathrm{mM}$ PAR.

\begin{tabular}{|c|c|c|c|c|}
\hline Anode Ipa1(X) & $\mathrm{X}^{\prime}$ & $\left(X-X^{\prime}\right)^{2}$ & (S) & (RSD) $\%$ \\
\hline 142.7 & \multirow{10}{*}{150.35} & 58.52 & \multirow{10}{*}{5.146} & \multirow{10}{*}{ $\pm 3.423 \%$} \\
\hline 144.4 & & 35.4 & & \\
\hline 146.1 & & 18.06 & & \\
\hline 147.8 & & 6.5 & & \\
\hline 149.5 & & 0.72 & & \\
\hline 151.2 & & 0.72 & & \\
\hline 152.9 & & 6.5 & & \\
\hline 154.6 & & 18.06 & & \\
\hline 156.3 & & 35.4 & & \\
\hline 158 & & 58.52 & & \\
\hline Anode Ipa2(X) & $\mathrm{X}^{\prime}$ & $\left(X-X^{\prime}\right)^{2}$ & (S) & (RSD) $\%$ \\
\hline 194.5 & \multirow{10}{*}{201.59} & 50.268 & \multirow{10}{*}{4.758} & \multirow{10}{*}{ $\pm 2.3604 \%$} \\
\hline 195.6 & & 35.88 & & \\
\hline 197.9 & & 13.61 & & \\
\hline 199.4 & & 4.79 & & \\
\hline 201 & & 0.34 & & \\
\hline 202.5 & & 0.82 & & \\
\hline 204 & & 5.8 & & \\
\hline 205.5 & & 15.28 & & \\
\hline 207 & & 29.26 & & \\
\hline 208.5 & & 47.74 & & \\
\hline Cathod & $\mathrm{X}^{\prime}$ & $\left(\mathrm{X}-\mathrm{X}^{\prime}\right)^{2}$ & (S) & (RSD) $\%$ \\
\hline
\end{tabular}




\begin{tabular}{|c|c|c|c|c|}
\hline $\operatorname{Ipc}(X)$ & & & & \\
\hline-107 & \multirow{10}{*}{-115.1} & 65.61 & \multirow{10}{*}{5.49} & \multirow{10}{*}{ $\pm 4.734 \%$} \\
\hline-108.8 & & 39.69 & & \\
\hline-110.6 & & 20.25 & & \\
\hline-112.4 & & 7.29 & & \\
\hline-114.2 & & 0.81 & & \\
\hline-116 & & 0.81 & & \\
\hline-117.8 & & 7.29 & & \\
\hline-119.6 & & 20.25 & & \\
\hline-121.4 & & 39.69 & & \\
\hline-123.2 & & 65.61 & & \\
\hline
\end{tabular}

\section{CONCLUSION}

Paracetamol compound was studied by cyclic voltammetric technique to find the electrochemical properties on the new modified working electrode (GCE) with fMWCNT in $\mathrm{KCl}$ solution at different concentrations, scan rates, $\mathrm{pH}$, and the reliability. Paracetamol drug which used as analgesic treatment was studied in the side of the oxidative and antioxidant reagent. Two oxidation current peaks were found in the cyclic voltammogram and these peaks have important properties in different $\mathrm{pH}$ which explain as extinguished in acidic medium and enhanced in alkaline $\mathrm{pH}$, also for reduction peak. So, paracetamol drug act as oxidative agent in alkaline medium and antioxidant in acidic medium.

\section{REFERENCES}

1 S.C. Sweetman. The Complete Drug Reference. 34th ed. London, UK: Pharmaceutical Press; 2005.

2 E. Rinaki, G. Valsami, P. Macheras. "Quantitative biopharmaceutics classification system: The central role of dose/solubility ratio." Pharm Res. 2003;20:1917-1925

3 E. E. Biazar, M. Rezayat, N. Montazer, K. Pourshamsian, R. Zeinali, A.Asefnejad, M. Rahimi, M. Zadehzare, M. Mahmoudi, R. Mazinani, M. Ziaei, "The effect of acetaminophen nanoparticles on liver toxicity in a rat model." In International Journal of Nanomedicine, 5(1), 197-201 (2010).

4 B. Uslu and S. A. Ozkan, "Electroanalytical Methods for the Determination of Pharmaceuticals: A Review of Recent Trends and Developments", Analytical Letters, (2011):44:16, 2644-2702

5 M. Sireesha, V. J. Babu , A. Sandeep K. Kiran and S. Ramakrishna, "A review on Carbon Nanotubes in Biosensor Devices and their Applications in Medicine". Nanocomposites, 4(2), 36-57(2018).

6 K. Balasubramanian , M. Burghard, "Chemically Functionalized Carbon Nanotubes". Small 1, 180-92 (2005).

7 S.K. Vashist, D. Zheng, K. Al-Rubeaan ,J. H.T. Luong, F-S. Sheu, "Advances in Carbon Nanotube Based Electrochemical Sensors for Bioanalytical
8 Applications". BiotechnologyAdvances, 29(2), 169188(2011). Z. Zhu , "An Overview of Carbon Nanotubes and Graphene for Biosensing Applications. Nano-Micro Lett". 9(25), 25-46 (2017).

9 R.W.Murray, A.G.Ewing, R.A.Durst, "Chemically modified electrodes. Molecular design for electroanalysis." Anal Chem. (1987) (pp.379-390)

10 S.Issac, K. K.Girish, "Voltammetric determination of sulfamethoxazole at a multiwalled carbon nanotube modified glassy carbon sensor and its application studies". Drug Test Anal. 2009;1(7):350-4

11 H. Filik, A. A.Avan, S.Aydar, G.Çetintaş. "Determination of Acetaminophen in the Presence of Ascorbic Acid Using a Glassy Carbon Electrode Modified with Poly(Caffeic acid)". Int. J. Electrochem. Sci., volume 9, page 148 - 160, (2014).

12 M. R. Muhammed., A. A.Mohammed, and S. J.Majid,. "Electrochemical Oxidation Effect of Nicotine in Cigarette Tobacco on a Blood Medium Mediated by GCE Using Cyclic Voltammetry". Portugaliae Electrochimica Acta 2020, 38(3), 139. 148

13 V.K. Gupta., R..Jain, K.Radhapyari, N.Jadon, S.Agarwal, "Voltammetric Techniques for the Assay of Pharmaceuticals-A Review". Analytical Biochemistry, 408, 179-196 (2011).

14 Chen C. C., and Hone J. Graphene nanoelectromechanical systems Proceedings of the IEEE. 101, 1766-1779 (2013).

15 F. Scholz and B. Meyer, "Electrochemical solid state analysis: state of the art", Chem. Soc. Rev., 1994, 23, 341.

16 M.Zidan, T. W.Tee, A. H.Abdullah, Z.Zainal, and G. J.Kheng, "Electrochemical oxidation of paracetamol mediated by nanoparticles bismuth oxide modified glassy carbon electrode", Int. J. Electrochem. Sci., vol. 6, no. 2, pp. 279-288, 2011.

17 H.Yin, K.Shang, X.Meng, and S. Ai, "Voltammetric sensing of paracetamol, dopamine and 4- 
aminophenol at a glassy carbon electrode coated with gold nanoparticles and an organophillic layered double hydroxide", Microchim. Acta, vol. 175, no. 12, pp. 39-46, 2011.

18 L. A.Alaa, M. R. Muhammed., N. K.Intesar, and N. N. Eman, "Azithromycin nanoparticles: Cyclic voltammetric study in human blood serum samples at electrochemical analysis", Romanian Journal of Neurology., Romanian Journal of Neurology Volume XIX, No. 1, 2020 (pp.12-18).

19 A.Babaei, M.Afrasiabi, S.Mirzakhani, and A. T.Reza, "A sensitive determination of acetaminophen in pharmaceutical preparations and biological samples using multi-walled carbon nanotube modified glassy carbon electrode", J. Braz. Chem. Soc., vol. 22, no. 2, pp. 344-351, 2011.

20 Z. M. N.Muhammad, S. Zdenek, P.Martin, "Effect of Electrolyte $\mathrm{pH}$ on the Inherent Electrochemistry of Layered Transition-Metal Dichalcogenides (MoS2, MoSe2, WS2, WSe2)", Volume2, Issue11, November 2015, Pages 1713-1718. 